\title{
Understanding Competencies and Competency Modeling - A Literature Survey
}

\author{
Vikram Singh Chouhan \& Sandeep Srivastava
}

\begin{abstract}
In a knowledge-based economy, the success of organizations depends mostly on the quality of their human resource. Organizations rely on their competent employees as a main resource. The performance of organizations depends not only on the workforce competency, but also on their evaluation and development on an ongoing basis to meet the global competition. For obvious economic and business reasons, organizations have always been concerned about the competence of its people. In the modern world, characterized by rapid and dramatic change, the attainment of competence has become an integral component of individual and organizational strategies. The competency mapping process helps the organization in developing a clear strategy for developing competencies of their workforce. It supports successful performance of the employees within the organization. Gone are the days where gigantic plant, superior technology and marketing strategy played central role in organizational success. The organizational strategy must be designed to identify, nourish and utilize the competencies. This paper seeks to delve deeper into the concept of competency, tracing its history and its role in the current scenario.
\end{abstract}

Keywords: competency, competency mapping, competency model, performance, literature review, strategies.

\section{Introduction}

Today organizations are all talking in terms of competence. Gone are the days when people used to talk in terms of skill sets, which would make their organizations competitive. There has been a shift in the strategy of the organizations. Now they believe in excelling and not just competing. It is better to build a core competency that will see them through the crisis. And what other way than to develop the people, for human resource is the most valuable resource any organization has. For over four decades now, competencies and competency models have become an inseparable part of Human resources management and have been widely used as a means for increasing personal and organizational efficiency. Competencies include the collection of success factors necessary for achieving important results in a specific job or work role in a particular organization. Competency refers to the intellectual, managerial, social and emotional competency. People are rewarded for their competencies (Spencer \& Spencer, 1993), which in turn are influenced by some personal antecedents (Bartram, 2005).

Competency Models are effective measurement tools that help employees agree on a common language and comprehend what is understood by superior performance. Moreover, Competency-based HRM is a core strategy to help align internal behavior and skills with the strategic direction of the organization as a whole. Competency models translate organizational strategies, goals and values into specific behaviors. Today organizations realized that if properly designed and skillfully handled, the competency model leads to individual and organizational performance enhancements and therefore helps the integration and promotion of all HRM practices. As the interest in measuring and predicting performance in the workplace has grown tremendously, the term "competency" appears to have become a staple part of an HR practitioner's vocabulary.

\section{History of Competencies}

Way back in 1953, David McClelland, an American management guru for the first time recognized a human trait that he called 'competence'. Robert White in 1959 and later McLagan, Richard Boyatzis, Signe Spencer and David Ulrich remarkably developed the concept of “competencies” for the organization's survival and sustained competitive advantage. In 1973, David McClelland, Professor of Psychology at Harvard University and founder of McBer and Company (now part of the Hay Group), wrote a seminal paper: "Testing for Competence Rather than Intelligence", which created a stir in the field of industrial psychology. McClelland's research indicated that although traditional academic aptitude and knowledge content tests were good predictors of academic performance, they seldom predicted on-the-job performance. It raised questions about the reliability of intelligence tests as a predictor of job success and stated that 'the correlation between intelligence test scores and job success often may be an artifact, the product of their joint association with class status'. McClelland went on to argue that the best predictors of outstanding on-the-job performance were underlying, enduring personal characteristics that he called "competencies". Since then, McClelland's findings 
have been cross-culturally validated by 30 years of global competency research carried out by McBer and later by the Hay Group. Hence, the history of competency can be traced to the early 1970s, when industrial psychologists and human resource managers were seeking ways to predict job performance.

McClelland launched the competency modeling movement in the USA by outlining an alternative to the accepted intelligence tests as an approach to predicting 'competence'. While McClelland's work (1973, 1998) was focused on applications in the educational sector, greater interest was shown in business and industry. McClelland's thinking provided a cogent argument against assuming that intelligence tests alone are sufficient to evaluate individual performance. It was the elements of accountability and performance inherent in his thinking that stimulated attention outside educational institutions. Since his study, the competence approach also has been widely utilized and applied in various areas, such as primary and secondary education, higher education, and organization studies. The use of the term competency and its meteoric rise to 'business speak' is credited to Richard Boyatzis (1982) and his book "The Competent Manager". Boyatzis defines competency as 'an underlying characteristic of a person which results in effective and/ or superior performance in a job'. An underlying characteristic, it is suggested, could include a motive, trait, skill, an aspect of one's self image or social role, or a body of knowledge. Spencer and Spencer, who furthered Boyatzis' original work define competency as an 'underlying characteristic of an individual that is causally related to criterion referenced effective and/or superior performance in a job or situation' (Spencer, 1993: 9).

After 18 years Gerald Bareeett and Robert Depinet came out with their paper "A Reconsideration for Testing for competence Rather than for Intelligence," in which, they argued that though McClelland and his associates believed that Intelligence testing should be replaced by competency based training since 18 years, they haven't been able to produce any professionally acceptable empirical evidence for the same.

In the recent years, many meanings and new labels have evolved through common usage for the term 'competence' and 'competency' (Strebler et al., 1997). The term 'competence' and 'competent' refer to a state or quality of being able and fit. Usually the term 'competency/competencies' has been used to refer to the meaning expressed as behaviors that an individual needs to demonstrate, while the term 'competence' has been used to refer to the meaning expressed as standards of performance (Hoffmann, 1999).

\subsection{Meaning of the Term "Competency"}

\section{Understanding Competencies}

Competency has its origins in the Latin word 'competentia' which means "is authorized to judge" as well as "has the right to speak" (Caupin et al., 2006: 9). The English dictionary defines the word 'competence' as the state of being suitably sufficient or fit. Trying to draw a fine line between the (buzz) words such as proficiency, capability, capacity, competence, competency/ competencies is even more difficult and creates confusion (see examples in Byham \& Moyer, 2000; Cooper, 2000; Mirabile, 1997).

Those who spend efforts in examining competency are immediately struck by the lack of uniform definitions, compositions, and methodologies which, of course, lead to misunderstanding, wandering, and waste (Cooper, 2000; Dalton, 1997). Its meanings defined by standard dictionaries are broad, vague, and inferred which subject to a variety of interpretations.

\subsection{Definitions by Authors}

The definition of competency is one of the most fraught tasks in business research, with little agreement among researchers.

McClelland (1973) presented data that traditional achievement and intelligence scores may not be able to predict job success and what is required is to profile the exact competencies required to perform a given job effectively and measure them using a variety of tests. He defined 'competence' as "a personal trait or set of habits that leads to more effective or superior job performance", in other words, an "ability that adds clear economic value to the efforts of a person on the job".

Klemp (1980) defined competency as, "an underlying characteristic of a person which results in effective and/or superior performance on the job".

Boyatzis $(1982,2007)$ adopted the term competency an "underlying characteristic of an individual that is casually (change in one variable cause change in another) related to superior performance in a job". He identified that there were 19 generic competencies that outstanding managers tend to have. He clubbed those 19 generic management competencies into five distinct clusters, as a goal and action management, leadership, human resource management, directing subordinates and focus on others.

Hornby and Thomas (1989): "Competency is the ability to perform effectively the functions associated with management in a work situation".

Jacobs (1989): "Competency is an observable skill or ability to complete a managerial task successfully".

Hogg B (1989): "Competencies are the characteristics of a manager that lead to the demonstration of skills and abilities, which result in effective performance within an occupational area. Competency also embodies the 
capacity of transfer skills and abilities from one area to another".

Spencer and Spencer (1993): "Competencies are skills \& abilities-things you can do -acquired through work experience, life experience, study or training".

Page and Wilson (1994) after reviewing 337 citations regarding competencies, defined it as "the skills, abilities, and personal characteristics required by an 'effective' or 'good' manager'. The point to note about this definition is the inclusion of directly observable and testable competencies, such as knowledge and skills, and the less assessable competencies related to personal characteristics or personal competencies.

Gilbert (1996) defined competence "as the state of being competent refers to having the ability to consistently produce the results (the worthy outcomes of behavior) that are required for the most efficient and effective achievement of the larger organizational goals".

Dubois (1998): "Competencies are those characteristics- knowledge, skills, mindsets, thought patterns, and the like-that, when used either singularly or in various combinations, result in successful performance".

Evarts (1998) defined competency as an "underlying characteristic of a manager which causally relates to his/her superior performance in the job".

Woodall and Winstanley (1998) maintain competency as "the skills, knowledge and understanding, qualities and attributes, sets of values, beliefs and attitudes which lead to effective managerial performance in a given context, situation or role".

Rice (2006) reflects on the leadership development among healthcare executives in the U.S. According to him, competency-based leadership development does not just drift, however it intentionally focuses on clear career aspirations. Meanwhile, he stressed that disciplined approach to career growth will enhance the organization's performance.

Lucian Cernusca and Cristina Dima (2007) in their research essay explained the concept of competency and how competency is linked to performance and one's career development. The authors also look into some models of competency mapping and appraisal tools for performance management. A business might possess extremely capable human resources, but they might not work on the position that suits them. This is where competency mapping and the appraisal tools come to help the HR experts choose who should work on what position.

Rothwell et al. (2004) addressed competency efforts in the USA programmes have evolved from an early focus on distinctions between best-in-class (exemplary) and fully-successful performers to become a link between organizational strategy and organizational and individual performance. Interests in competency-based approaches are growing. Training and development professionals are using competency models to clarify organization-specific competencies to improve human performance and unify individual capabilities with organizational core competencies.

Gaspar (2012) found that Competency based selection method is healthy, structured and comprehensive. Candidates are evaluated on the competencies they need to demonstrate, when inducted into the organization. The performance management, competency system diagnoses the future training and development needs of the employees and it helps the HR executives assist employees in decisions like promotions and transfers.

Many definitions of the term "competency" have risen over the past decade. The definition that is most preferred is as follows: "Competencies include the collection of success factors necessary for achieving important results in a specific job or work role in a particular organization". Success factors are combinations of knowledge, skills, and abilities (more historically called "KSA's") that are described in terms of specific behaviors, and are demonstrated by superior performers in those jobs or work roles.

Although the meaning and definition of the term 'competency' is still subject to debate (Shippman et al., 2000), for the purposes of our study, we adopted the definition proposed by Bartram, Robertson, and Callinan (2002), which states that competencies are "sets of behaviors that are instrumental in the delivery of desired results or outcomes" (p. 7). Competencies conceptualized in such a way are "something that people actually do and can be observed" (Campbell et al., 1993, p. 40). A competency is the capability of applying or using knowledge, skills, abilities, behaviors, and personal characteristics to successfully perform critical work tasks, specific functions, or operate in a given role or position. Competencies are thus underlying characteristics of people that indicate ways of behaving or thinking, which generalizes across a wide range of situations and endure for long periods of time.

\subsection{Five Types of Competency Characteristics}

There are five major components of competency (Tucker and Cofsky, 1994);

1) Knowledge-This refers to information and learning resting in a person, such as surgeon's knowledge of Human Anatomy.

2) Skill-This refers to a person's ability to perform a certain task, such as surgeon's skill to perform a surgery.

3) Self Concepts and Values-This refers to a person's attitudes, values and self image. An example is self confidence, a person's belief that he or she can be successful in a given situation, such as a surgeons self 
confidence in carrying out a complex surgery.

4) Traits-Traits refer to physical characteristics and consistent responses to situations or information. Good eyesight is a necessary trait for surgeons, as is self control is an ability to remain calm under stress.

5) Motives-Motives are emotions, desires, physiological needs or similar impulses that prompt action. For example, surgeons with high interpersonal orientation take personal responsibility for working well with other members of the operating team.

Motives and Traits may be termed as initiators what people will do on the job without close supervision. As shown in figure 1, the resultant of a critical behavior is higher performance. The level of performance (low, moderate or high) is always determined by the level of knowledge, skill and attitude.

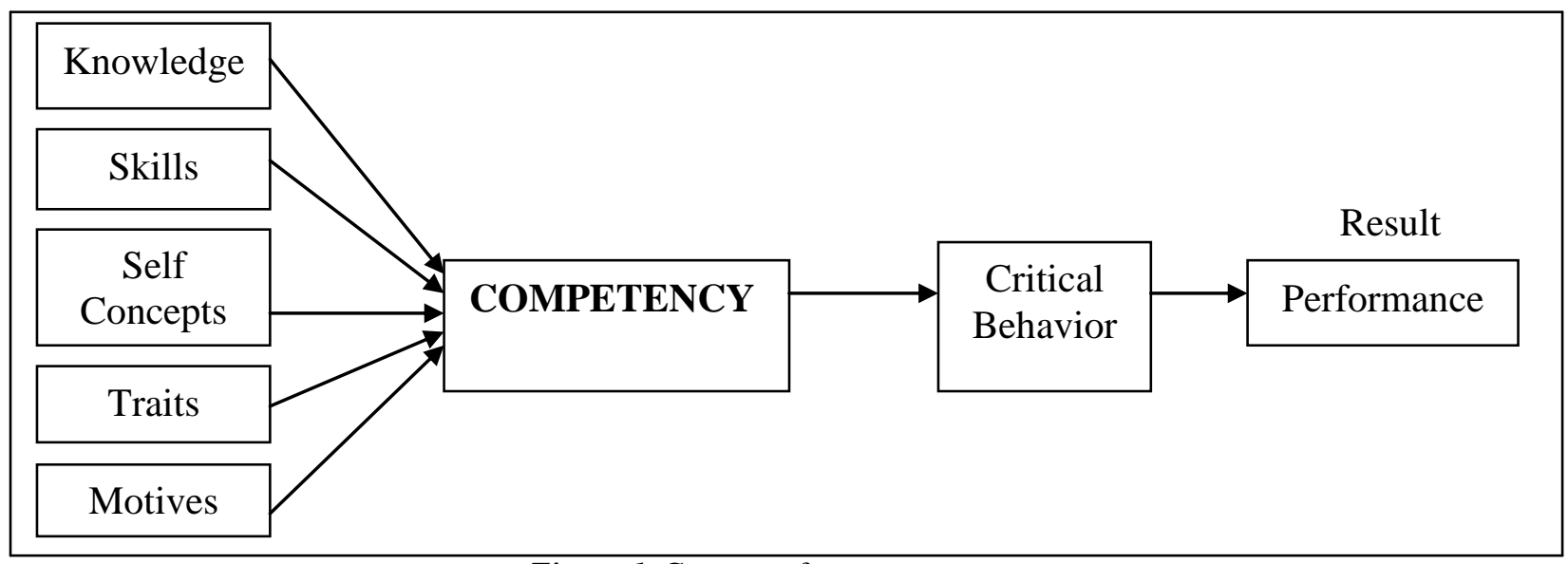

Figure 1. Concept of competency

\subsection{Classification of Competencies}

In order to set the context of theoretically derived competence classes, a brief review is given regarding some of the classification patterns. In literature different patterns for classification of competencies are given. Most often, researchers define categorization according to their own theory and purpose of the study.

Katz and Kahn (1986) grouped competency into three areas which later expanded into the following four:

1) Technical or Functional (knowledge, attitudes, skills, etc. associated with the technology or functional expertise required to perform the role);

2) Managerial (knowledge, attitudes, skills, etc. required to plan, organize, mobilize and utilize various resources);

3) Human (knowledge, attitudes and skills required to motivate, utilize and develop human resources); and

4) Conceptual (abilities to visualize the invisible, think at abstract levels and use the thinking to plan future business).

Carrol and McCrackin (1988) organized competencies into three main categories.

1) Core competencies (Hamel and Prahalad, 1994): A core competency forms the basis for strategic direction; it is something a company does well relative to other competitors. Core competencies refer to the elements of behavior that are important for all employees to possess as, for example, a core competency in "result/ quality orientation".

2) Leadership / managerial competencies: This category involves competencies that are related to leading an organization and people. Some examples include "visionary leadership", "strategic thinking", and "developing people".

3) Functional competencies: These are job-specific skills required to perform a particular job role or profession (Ozcelik and Ferman, 2006:75).

\subsection{Competency Mapping}

'Competency mapping' is a process of identifying key competencies for a company or institution and the jobs and functions within it. Competency mapping is used to identify key attributes (knowledge, skills, and behavior) that are required to effectively perform job classification or any identified process. Competency mapping analyzes individual's SWOT (Strengths, Weaknesses, Opportunities \& Threats) for better understanding and this helps to improve his career growth. It consists of breaking a given role or job into its 
constituent tasks or activities and identifying the competencies (technical, managerial, behavioral, conceptual knowledge, an attitudes, skills, etc.) needed to perform the same successfully. Competency mapping determines the extent to which the various competencies related to a job are possessed by an employee. Competency mapping envisages development and sustainability of competency, based on the changing organizational requirements. Therefore, competency mapping is a process a HR expert uses to identify and describe competencies that are most crucial to success in a work situation. Competency mapping is one of the most accurate means in identifying the job and behavioral competencies of an individual in an organization. Companies are vastly shifting their strategy of having multi-skilled employees with knowledge of only one skill. The competence approach focuses on linking business strategies to individual performance efforts. Development of employees focuses on enhancing their competencies rather than preparing them for moving to jobs. In this way they can develop capabilities useful throughout the organization as it changes and evolves.

\subsection{Competency Model}

A Competency model is a valid, observable, and measurable list of the knowledge, skills, and attributes demonstrated through behavior that results in outstanding performance in a particular work context. Competency model is a set of competencies that include the key behaviors required for excellent performance in a particular role (Lucian Cernusca and Cristina Dima, 2007). Depending on the work and organizational environment, a group of 7 to 9 total competencies are usually required for a particular job and depicted in a competency model (Shippman et al., 2000). A competency model is an organizing framework that lists competencies required for effective performance in a specific job, job family (e.g., a group of related jobs), and organization. The model is organized into tiers of competencies and includes descriptions of the activities and behaviors associated with each competency. Competency models are often highly tailored to the organization. As such, the elements of a competency model communicate, in clear terms, the circumstances and conditions of performance. Individual competencies are organized into competency models to enable people in an organization or profession to understand, discuss, and apply the competencies to workforce performance.

\section{Review of Literature}

Our study has reviewed global leading articles on the topic for the purpose of gaining in-depth insight into the competency mapping in organizations. Here is the snapshot of the extensive literature survey.

Any analysis of competencies requires careful definition because of the considerable variance in the use of the term 'competencies' in the literature. For the purpose of this study, the numerous definitions of competency can be summarized effectively as a collection of technical and cultural capabilities (Brockbank 1997). However, it is obvious throughout the literature that different authors advocate different approaches to competency definition. For example, one particular approach to modeling competencies advocated by Ulrich et al. (1995) and Boyatzis (1996) includes the integration of areas of competence into groupings. Ulrich carried out a large-scale survey in the US looking at specific competencies in HR in order to produce benchmarking standards. There was the emergence of the HR business partner model resulting in a need for the professional growth of HR practitioners themselves, and the need to contribute to the organization's competitive stance as a whole. Ulrich defined competence as the ability to add value to the business; competence must focus on the process leading from changing business conditions to achieve sustainable competitive advantage. Ulrich et al. (1995) model combines various aspects of competence into three primary elements: knowledge of the business, HR functional expertise and management of change. They argue that management of change is critical, as the organization's external rate of change (e.g. Globalization, information flow, customer expectations, technology, etc.) must be matched by the internal rate of change for the organization to remain competitive. Irrespective of job role or job title, the elements of competence remain in the same order of importance, with any variation manifesting itself in weight alone. In the definition of the models it is already clear how individuals carrying out different models of personnel management will require different degrees of competence in different areas. Many studies focused on hierarchical and functional differences in managerial work. Pinto (1975) identified through factor analysis 13 independent dimensions of managerial responsibilities and found that upper level managers have undertaken more of planning, public and customer relations advanced consulting and broad personnel responsibilities when compared to middle and begin level managers. Whitley (1989) concluded that managerial work is closely linked to industrial context and cannot be easily isolated from their context and standardized across enterprises and industries. Studies comparing managers from different nations and environmental conditions reinforce this view. The content of managerial work across nations was found to be similar but actual performance seems to be context dependent. Rankin (2002) carried out an analysis of the core competency frameworks of 40 employers showed that 433 competencies were named in total. Suar \& Dan (2001) identified 47 competencies for different jobs. These competencies were relating to nine broad categories Aptitudes, Skills and abilities, Communication, Leadership, Knowledge, Physical competency, Personality, Principles and values and Interests. Parveen (2002) established organizations with an expanded role for HR, 
ranked advising on HR issues as the most important competency. Ranjekar (2003) portrayed the relationship between possession of HR competencies and credibility. The list of important HR competencies for being credible is suggested, which includes; Sound subject knowledge, Personal work habits and productivity, Fearlessness, Care and sensitivity, Playing it low key and Comfort with dilemmas and ambiguities. There are three components of credibility for a function or an organization, personal credibility, group credibility (how many members in that group have high personal credibility) and most importantly the consistency of such credibility. Richard (2003) related competencies to success in the role of HR, which includes Networking and internal consultancy, Interpersonal sensitivity, Theoretical basis, Strategic perspective, Systems and process orientation, Quantitative analysis and Project management.

Since the pioneering work of Stogdill (1948), Katz (1955), and Mann (1965) on competencies, a burgeoning literature in the 1980s and 1990s has gone on to identify an array of competencies linked to managerial success and effective performance (e.g., Boyatzis, 1982; Du Gay, Salaman,\& Rees, 1996; Lawler, 1994; Mansfield, 1996; McCall \& Lombardo, 1983; McLagan, 1996;Mirabile, 1997; Spencer \& Spencer, 1993). However, even if competency-driven applications have been applauded by many organizations, some authors have complained about the unbalanced relationship between the abundance of competency models used in organizational settings and the paucity of empirical research studies that have been conducted to support them (Laber \& O'Connor, 2000). Within the field, systematic research on how competencies can be grouped into higher order dimensions is considered to be crucial for the development of a meaningful structure at work, and scholars are turning attention to theorize and empirically investigate on this issue (e.g., Borman \& Brush, 1993; Campbell, McCloy, Oppler, \& Sager, 1993; Shipper \& Davy, 2002; Tornow \& Pinto, 1976).

The latest HR competency model by Dave Ulrich (2012) proposes that HR professionals must master six competencies: Credible activist; Strategic positioner; Capability builder; Change champion; Human resource innovator and integrator; and Technology proponent. These competencies are based on research from more than 20,000 respondents (HR professionals and their line and HR associates) around the world, who completed assessments of HR competence on 140 behavioral and knowledge items.

Competency models are too often a -medley of job KSAs-_ill-defined concepts with no clear meaning (Sackett \& Laczo, 2003). Competency modeling does not inherently lack rigor. However, most early efforts were conducted by less methodologically rigorous consultants who were not researchers. They had many key advantages such as a broader view of management and perhaps better rapport with management because of this. Competency modeling becomes a popular management topic (Alldredge, \& Nilan, 2000; Bartlett \& Ghoshal, 1997; Kochanski, 1997; Mirabile, 1997; Pickett, 1998; Punnitamai, 1996; Shippman et al., 2000; Winterton, \& Winterton, 1999). Thousands of organizations throughout the world have joined the quest for competency studies (Bemthal \& Wellins, 2001; Cooper, 2000; Dubois, 1998).

\section{Strategies for the Development of Competency Models}

There are three approaches for building competency models-

The single-job approach: The first competency models were developed for single jobs and are the most common approach to competency modeling. Developing a single-job competency model starts with an identified critical job that line management or an HR professional sees as needing better selected or developed incumbents. The data collection usually includes the resource panel or focus group of job holders and/or their managers and interviews with jobholders. The data gathering phase may also include interviews with customers and direct reports, surveys of additional job holders, and direct observation of job holders at work. Once this is complete, the next step is to analyze the data to distill it into a competency model that typically includes 10-20 traits or skills, each with a definition and a list of specific behaviors that describe what effective performers do and how to achieve effective results.

The "one-size-fits-all" approach: HR professionals who are seeking a broad, quick, and consistent impact for competency technology often adopt a "one-size-fits-all" competency model, by defining one set of competencies for a broad range of jobs (e.g., all managerial jobs). The first step is to identify the population for whom the model will apply, such as all managers. Instead of gathering data, a team charged with developing the competency model usually selects concepts from available individual job competency models and from books and articles on leadership, business, organizational development, and human resource development.

A multiple-job approach: This method creates multiple models depending on jobs and levels. This method is used when all the jobs do not have anything in common. To go ahead with creating models that are of use, the organization has to be more specific on the potential uses of the model. The time is ripe for a multiple-job approach to building competency models. There is the requirement of such an approach and assumes, for example, that an organization needs competency models for 25 professional and managerial jobs, as well as consistent programs and tools for performance management, professional development, and selection for these jobs, based on the competency models. 


\section{Future Directions in the Development of Competency Models}

The three approaches described are likely to become more widely used, because they all offer ways to unify and integrate a variety of HR programs. The single-job competency model provides a way to improve the development and selection for a job seen as critical to the organization's success. The "one-size-fits-all" approach to building competency models has the advantage of providing a simple, unifying framework of all HR programs for a family of jobs, such as managerial. This approach is more difficult to implement, because it usually requires approval of top management and may also require the agreement of several independent HR groups. Implementing this approach, therefore, requires an effective champion from the HR function or from line management. The multiple-job approach to developing competencies offers the dual advantages of a common conceptual framework and customization for individual jobs. This is the only approach that facilitates comparison of competency models with each other and comparison of employee profiles with multiple jobs. The multiple job approach is more cost effective than the single-job approach, if many competency models are needed, but the multiple-job approach is the most difficult of the three approaches to implement.

\section{Linking Competency Models to Organizational Goals and Objectives}

Competencies must be typically linked to business objectives and strategies (e.g., Campion et al., 2011; Martone, 2003). The business objectives linkage of competency models is critical to the interest and commitment of senior management. In addition, the business linkage distinguishes competency models from job analysis, which usually stops short of translating how the competencies directly influence organizational goals. In order to ensure that the best practices are met, the development of the competency model often starts with a definition of the organizational goals and objectives. Based on the guiding framework, competencies critical for obtaining those goals and objectives are identified (figure 2). Sometimes the competencies are direct translations of the organizational goals. Other times, the competencies might be one step back in the chain of efforts required for the organizational goals, such as the identification of innovative new products. Note that this best practice does not preclude the inclusion of some competencies that relate to the fundamental requirements of organizations that are not necessarily linked to specific organizational goals, such as producing high-quality products or services. Competencies of this nature are more common for lower-level jobs, whereas competencies more clearly related to organizational goals are more apparent for management and executive jobs.

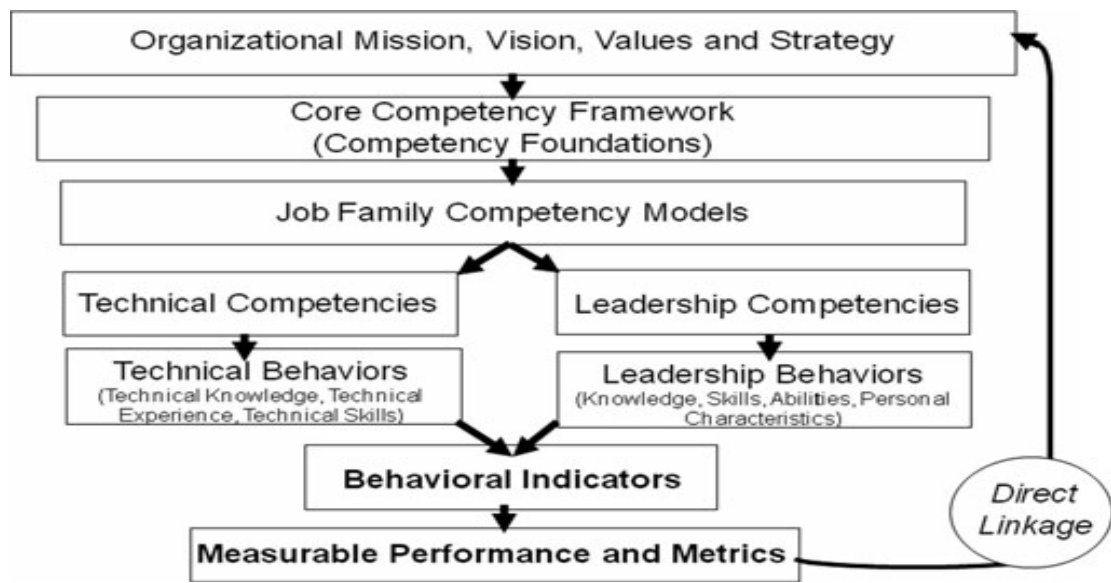

Figure 2. A Framework for Competencies (Campion M.A. et al., 2011)

\section{Conclusion}

From this critical literature review, it should be clear that the development and use of competencies is a complex endeavor. The development and application of a competency model is the proven approach to investing in human resources in order to achieve a more effective and productive workforce. The functioning of an organization largely depends upon several remarkable components, with the talented employee occupying the central role in the accomplishment of organizational goals. In the present economic scenario, the need for a forward-looking and proactive approach to competency modeling is driven by the increasing pace of change in the business environment. Competencies can be used for translating strategy into job-related and individual skills and behaviors that people easily can understand and therefore implement. With the knowledge and use of the information contained within a competency model and awareness of their individual competency strengths and weaknesses, individuals may manage their future job or career success, navigate their current chosen career pathway, or apply the information to examine new career opportunities, considering the utilization of transferable competencies. 
We hope that describing the competencies and illustrating them through the applications of the models will promote good practice around competencies. We believe this extensive literature survey can guide and encourage more effective and efficient use of competencies and also inspire greater empirical research on competencies.

\section{References}

[1]. Alldredge, M.E., \& Nilan, K.J. (2000). 3M's leadership competency model: An internally developed solution. Human Resource Management, 39,133 - 145.

[2]. Bartlett, C. A., \& Ghoshal, S. (1997). The myth of the generic manager: New personal competencies for new management roles. California Management Review, 40, $92-116$.

[3]. Bartram, D. (2005). The great eight competencies: A criterion-centric approach to validation. Journal of Applied Psychology, 90, 1185-1203.

[4]. Bartram, D., Robertson, I. T., \& Callinan, M. (2002). Introduction: A framework for examining organizational effectiveness. In I. T. Robertson, M. Callinan, \& D. Bartram (Eds.), Organizational effectiveness: The role of psychology (pp. 1-10). Chichester, UK: Wiley.

[5]. Bernthal, P.R., \& Wellins, R.S. (2001). Leadership forecast 2001: A benchmarking study. Pittsburgh, PA: Development Dimensions International.

[6]. Borman, W. C., \& Brush, D. H. (1993). More progress toward a taxonomy of managerial performance requirements. Human Performance, 6, 1-21.

[7]. Boyatzis, R. (1982). The Competent Manager. New York: John Wiley.

[8]. Boyatzis, R. (2007). Competencies in the 21st century. Journal of Management Development, 27(1): 5-12.

[9]. Boyatzis, R. (1996). Competencies for HR professionals: An interview by A.K. Yeung. Human Resource Management, 35,35 51.

[10]. Brockbank, W., Ulrich, D. \& James, C. (1997). Trends in human resource competencies. Ann Arbor: University of Michigan School of Business.

[11]. Byham \& Moyer (2000). "Developing Dimension/Competency-Based Human Resource Systems", A Monograph.

[12]. Campbell, J. P., McCloy, R. A., Oppler, S. H., \& Sager, C. E. (1993). A theory of performance. In N. Schmitt \& W. C. Borman (Eds.), Personnel selection in organizations (pp. 35-70). San Francisco: Jossey-Bass.

[13]. Campion, M.A., Fink, A.A., Ruggeberg, B.J., Carr, L., Phillips, G.M., \& Odman, R.B. (2011). Doing competencies well: Best practices in competency modeling. Personnel Psychology, 64, 225-262.

[14]. Caupin (2006). ICB - IPMA Competence Baseline, International Project Management Association.

[15]. Cooper, K. E. (2000). Effective competency modeling and reporting: A step-by - step guide for improving individual and organizational performance. New York: AMACOM.

[16]. Dalton, M. (1997). Are competency models a waste? Training and Development, 51(10): 46-49.

[17]. Du Gay, P., Salaman, G., \& Rees, B. (1996). The conduct of management and the management of conduct: Contemporary managerial discourse and the constitution of the 'competent' manager. Journal of Management Studies, 33, $263-282$.

[18]. Dubois D. (1998). Competency-based HR Management. Black Well Publishing.

[19]. Evarts H. (1988). The Competency Programme of the American Management Association. Journal of Management Development, 7, 48-56.

[20]. Gaspar Robert (2012). A Study on the Perception of Human Resource Executives On Competency Mapping for the Superior Results. International Journal of Social Science Tomorrow, 1(8).

[21]. Gerald Barrett (1982). A Reconsideration of Testing for competence Rather than for Intelligence. -3.

[22]. Gilbert, T. (1996). Human competence. Silver Spring, MD: International Society for Performance Improvement

[23]. Hamel, G., \& Prahalad, C.K. (1994). Competing for the future. Harvard Business School Press, Boston

[24]. Hoffman T. (1999). The Meaning of Competency. Journal of European Industrial Training, 23(6): 25-286.

[25]. Hogg B. (1989). Realizing the Potential of Your Employees through Assessment and Development. London: Tata- McGraw-Hill Training Series.

[26]. Hornby D. and Thomas R. (1989). Toward a Better Standard of Management. Personnel Management, 21 (1): $52-55$.

[27]. Jacobs R. (1989). Getting the Measure of Management Competence. Personnel Management, 21 (6): 32-37.

[28]. Katz Daniel and Kahn Robert (1966). The Social Psychology of Organizations. John Wiley \& Sons, New York.

[29]. Katz, R. L. (1955). Skills of an effective administrator. Harvard Business Review, 33, 33-42.

[30]. Klemp, G.O. (1980). The assessment of occupational competence. Washington, D.C.: Report of the National Institute of Education.

[31]. Laber, M. E., \& O'Connor, J.K. (2000). Competency modeling: Ready, set, research. The Industrial-Organizational Psychologist, 37, 91-96.

[32]. Lawler E. (1994). From job-based to competency-based organizations. Journal of Organizational Behavior, $15,3-15$.

[33]. Lepsinger, R., and Lucia A. D. (1999). The art and science of competency models: Pinpointing critical success factors in organizations. San Francisco, Jossey- Bass/Pfeiffer.

[34]. Mann, F. C. (1965). Toward an understanding of the leadership role in formal organization. San Francisco: Chandler.

[35]. Mansfield, R. S. (1996). Building competency models: Approaches for HR professionals. Human Resource Management, 35, 718.

[36]. Martone D. (2003). A guide to developing a competency-based performance-management system. Employment Relations Today, $30,23-32$.

[37]. McCall, M. W., \& Lombardo, M. M. (1983). Off the track: Why and how successful executives get derailed. Greensboro, NC: Center for Creative Leadership.

[38]. McClelland D.C. (1973). Testing for Competence Rather Than for Intelligence. American Psychologist, 28 (1): 1-14.

[39]. McClelland D.C. (1975). A Competency Model for HR Management Specialists to be used in the Delivery of the Human Resource Management Cycle. McBer, Boston.

[40]. McClelland D.C. (1998). Identifying competencies with behavioral event interviews. Psychological Sciences, 9, 331-339.

[41]. McLagan, P. (1996). Great ideas revisited: competency models. Training and Development, 50, 60-64.

[42]. Mirabile, R. J. (1997). Everything you wanted to know about competency modeling. Training and Development, 73-77.

[43]. Page C. and Wilson (1994). Management Competencies in New Zealand. On the inside looking in Wellington. Ministry of Commerce - 5 . 
[44]. Parveen, N. (2002). Smart Enough for IT. Human Capital, 5 (10): 56-60.

[45]. Pickett, L. (1998). Competencies and managerial effectiveness. Public Personnel Management, 27, 103 - 115.

[46]. Pinto, P.P. (1975). Job Descriptions for Executives-Revisited. Academy of management Proceedings, 228-230.

[47]. Punnitamai, W. (1996). A competency-based model of the Thai "new wave" leaders: Strategies for identification and development of management talent. A paper presented at the ASEAN Conference on the New Wave Leaders: Chaingmai, Thailand.

[48]. Ranjekar, D. (2003). Got to build Faith. Human Capital, 7 (1): $42-44$.

[49]. Rankin, N. (2002). Raising performance through people: The ninth competency survey. Competency and Emotional Intelligence, pp 2-21.

[50]. Rice, James (2006). Career and Competency Mapping. Healthcare Executive, 21 (6): 52-55.

[51]. Rothwell, W., Bernthal, Paul R., Colteryahn, Karen, Davis, Patty, Naughton, Jennifer, \& Wellins, Rich (2004). ASTD competency study: Mapping the future. Virginia: ASTD Press.

[52]. Sackett, P.R., \& Laczo, R.M. (2003). Job and work analysis. In W.C. Borman, D.R. Ilgen, and R.J. Klimoski (Eds.). Handbook of psychology: Industrial and Organizational Psychology (Vol. 12, pp. 21-37), NJ: Wiley.

[53]. Schippmann J.S., Ash R.A., Battista M., Carr L., Eyde L.D., Hesketh B., Kehoe, J. Pearlman, K. \& Sanchez I. (2000). The practice of competency modeling. Personnel psychology, 53, 703-740.

[54]. Shipper, F., \& Davy, J. (2002). A model of investigation of managerial skills, employees' attitudes, and managerial performance. Leadership Quarterly, 13, 95-120.

[55]. Spencer L. \& Spencer S. (1993). Competence at Work: Model for Superior Performance. John Wiley \& Sons, New York.

[56]. Stogdill, R. M. (1948). Personal factors associated with leadership: A survey of the literature. Journal of Psychology, 25, 35-71.

[57]. Strebler M, Robinson D. \& Heron P. (1997). Getting the Best Out of Competencies. Institute of Employment Studies Report, 334, Brighton.

[58]. Suar, D. \& Dan, A. (2001). Competency Assessment and Need Identification for Training. IJTD Journal, XXXI (4): 68-76.

[59]. Tornow, W. W., \& Pinto, P. R. (1976). The development of managerial job taxonomy: A system for describing, classifying and evaluating executive positions. Journal of Applied Psychology, 61, 410-418.

[60]. Tucker, S., \& Cofsky K. (1994). Competency-Based Pay on a Banding Platform. ACA Journal, 3 (1).

[61]. Ulrich, D., Brockbank, W., \& Johnson, D. (2008). HR Competencies: Mastery at the Intersection of People and Business, Alexandria, VA: Society of Human Resource Management.

[62]. Ulrich, D., Brockbank, W., Yeung, A. \& Lake, D. (1995). Human resource competencies and empirical assessment. Human Resources Management, 34(4), 473-496.

[63]. Whitley, R. (1989). On the Nature of Managerial Tasks and Skills: Their Distinguishing Characteristics and Organization. Journal of Management Studies, 26(3): 209-224.

[64]. Winterton, J. \& Winterton, R. (1999). Developing managerial competence. London: Routledge

[65]. Woodall, J. \& Winstanley, D. (1998). Management Development: Strategy and Practice. Blackwell Publishers, Oxford. 